Discussion Paper No. 625

\title{
WHY COMMERCIAL BANKS HELD \\ EXCESS RESERVES: \\ THE JAPANESE EXPERIENCE OF \\ THE LATE '90s
}

Kazuo Ogawa

December 2004

The Institute of Social and Economic Research Osaka University

6-1 Mihogaoka, Ibaraki, Osaka 567-0047, Japan 
December 2004

\title{
Why Commercial Banks Held Excess Reserves:
}

\section{The Japanese Experience of the Late '90s*}

\author{
Kazuo Ogawa \\ Institute of Social and Economic Research, \\ Osaka University
}

* This is a substantial revision of the paper I submitted to the Financial Research Council. I am grateful to Hiroshi Fujiki, Shin-ichi Fukuda, Hideo Hayakawa, Nobuo Inaba, Kazumasa Iwata, Toshiki Jinushi, Keimei Kaizuka, Hiroshi Koyama, Ryuzo Miyao, Hiroshi Nakaso, Kunio Okina, Yoshinori Shimizu, Etsuro Shioji, Shigenori Shiratsuka, Hisashi Tanizaki, Juro Teranishi, Fukujyu Yamazaki, Jyunji Yano, Yukihiro Yasuda and the participants of the seminars at the Bank of Japan and Kobe University for extremely valuable comments and suggestions on early version of the paper. This research was partially supported by Grants-in-Aid for Scientific Research 12124207 of the Ministry of Education. 


\begin{abstract}
We investigated, empirically, why Japanese banks held excess reserves in the late 1990s. Specifically, we pin down two factors explaining the demand for excess reserves: a low short-term interest rate, or call rate, and the fragile financial health of banks. The virtually zero call rate increased the demand for excess reserves substantially, and a high bad loans ratio largely contributed to the increase in excess reserve holdings. We found that the holdings of excess reserves would fall by half if the call rate were to be raised to its level prior to the adoption of the zero-interest-rate policy, and the bad loans ratio were to fall by $50 \%$.
\end{abstract}

JEL Classification Number: E42, E51, E52, and G21

Keywords: Excess Reserve, Bad loans, Zero-interest-rate-policy

Correspondence to:

Institute of Social and Economic Research, Osaka University, 6-1 Mihogaoka, Ibaraki, Osaka, 567-0047 JAPAN

Tel: +81- 6- 6879-8570 Fax: +81- 6-6878-2766

E-mail: ogawa@iser.osaka-u.ac.jp 


\section{Introduction}

Japanese banks have chronically held excess reserves since the late '90s. Figure 1 illustrates the ratio of actual reserves to required reserves for commercial banks as a whole. The increasing trend in the excess reserve ratio has been conspicuous since the summer of 2001, and this ratio reached a high of 5.88 in October 2003. ${ }^{1}$ The excess reserve ratio typically parallels the supply of reserves. In fact, the reserve supply began to increase when the Bank of Japan announced that it would provide ample funds to push down the uncollateralized overnight call rate, or short-term inter-bank money market rate, as low as possible, in February 1999. This action is known as the "zero-interest-rate policy.” Furthermore, the reserve supply drastically increased after the Bank of Japan (BOJ) switched its operating target for money market operations from the uncollateralized overnight call rate to the outstanding balances of the current accounts held at the BOJ in March 2001. The target level of outstanding balances of the BOJ's current accounts was valued at around five trillion yen in March 2001, but then rose to between 30 and 35 trillion yen by January 2004.

However, it should be noted that the reserve supply does not necessarily automatically create a demand for reserves. The aim of this study, therefore, was to shed light on the demand side of reserves and to conduct an empirical investigation into why commercial banks hold excess reserves. In actual fact, banks have their own motives for holding excess reserves. We identified two factors that may have affected banks' reserve demands since the late ' 90 s. The first of these factors is the nearly zero level of the call rate: the uncollateralized overnight call rate was pushed down to its minimum level after the adoption of the zero-interest-rate policy. Reserves and call loans are close substitutes; as a result, banks have more incentive to hold reserves when the call rate is very low.

The second relevant factor is the instability of the financial system. Ever since the outbreak of financial institution debacles in the late '90s, depositors have been very cautious about choosing which banks to deposit their money in. This implies that, in general, once the balance sheet of a bank deteriorates, depositors will switch deposits from one bank to another, more healthy one. Therefore, banks with fragile balance sheets have an incentive to hold reserves, for precautionary reasons. ${ }^{2}$ Incorporating these factors, 
we constructed a simple theoretical model of bank reserve demand. Using a panel dataset for banks, we estimated these banks' optimal demand functions for reserves, as derived from the theoretical model. The quantitative importance of the aforementioned two factors was evaluated by means of a simulation analysis, based on the parameter estimates in the banks' reserve demand functions. ${ }^{3}$

Our main findings may be summarized as follows. Using a theoretical model, we were able to derive each bank's optimal demand for reserves, which is a decreasing function of the short-term interest rate and an increasing function of the bank's financial health, represented by either its bad loan ratio or the rate of change in its share price. It turned out that both factors significantly impact banks' reserve demands, as suggested by the theoretical model. Quantitatively, the effect of the short-term interest rate on reserve demand was quite large. We found that raising the call rate to $0.05 \%$, its level just before the adoption of the zero-interest-rate policy, decreased the demand for excess reserves in the banking sector as a whole by as much as $30-40 \%$. The effect of a bank's financial health on its excess reserve demand was also significant. Excess reserves were reduced by $13-29 \%$ when the bad loan ratio was halved; this constitutes the goal to be attained by the end of FY 2004 in the Program for Financial Revival, under the Koizumi Administration.

The paper is organized as follows. The next section provides descriptive statistics for the banks' reserve holdings, which are based on the panel dataset for the Japanese commercial banks used in our study. Section 3 constructs a simple theoretical model of reserve demand and derives the optimal demand equation for reserves, which are to be estimated. Section 4 presents the estimation results, and Section 5 conducts a simulation analysis, based on the estimation results from the previous section, in order to evaluate quantitatively the effects of the short-term interest rate and bank financial health on excess reserve demand. Section 6 concludes the study.

\section{To What Extent Did Banks Hold Excess Reserves?}

We first calculated the extent to which commercial banks held excess reserves using panel data for Japanese banks during the period FY 1991 to 2002. We compared the 
actual reserve holdings at the end of each fiscal year with the reserves required at that time. The required reserves were calculated as follows. The reserve requirement ratios for deposits depend upon the type and amount of deposits, as is shown in Table 1. For example, when a bank holds three trillion yen as time deposits, the bank should hold 18.275 billion yen $(=(3000-2500) \times 0.012+(2500-1200) \times 0.009+(1200-500) \times 0.0005+$ $(500-50) \times 0.0005)$ as required reserves.

The required reserves at the end of a fiscal year are computed for each bank in our panel dataset, and compared with the actual reserve balance, to gauge the extent to which banks hold excess reserves. Our panel data set consists of 145 banks, of which nine are city banks, three are long-term credit banks, seven are trusts, and 126 are regional banks. Merged and/or insolvent banks were excluded from the sample. Therefore, our dataset constitutes an unbalanced panel. The sample period covers the years from FY 1991 to FY 2002. Table 2 presents descriptive statistics of the extent to which banks held excess reserves. The median of the ratio of actual reserves to required reserves was less than one until 1996, while it exceeded this value after 1997. It should be noted that the year in which the excess reserve ratio began to exceed one was characterized by a number of bankruptcies of financial institutions. It is likely that banks held excess reserves for precautionary purposes, to meet the demands of depositors switching from unhealthy banks to healthy ones.

In 2001, the excess reserve ratio again exhibited a sharp increase. The median of the excess reserve ratio in 2001 was about twelve times as large as that in 2000. This sharp increase coincided with the BOJ's switch of monetary policy target: from the short-term interest rate to the outstanding balances of the current accounts at the BOJ, constituting the so-called "quantitative easing" of monetary policy. Under the new monetary policy regime, the BOJ increased the monetary base substantially.

The standard deviation of the excess reserve ratio also increased after the middle of the '90s, suggesting that there were diverse reserve holding patterns across banks. This fact may also be inferred from Figure 2, which illustrates the frequency distribution of the excess reserve ratios in 1994, 1999 and 2001. The frequency distribution was more dispersed and less skewed to the right in later years. 


\section{A Model of Bank Demand for Reserves}

Consider a bank $i$, which allocates a given amount of deposits $\left(D_{i}\right)$ to an interest-bearing asset, and with reserves at a central bank bearing no interest, under the stochastic withdrawal of deposits. ${ }^{4}$ By allocating all of its deposits to the interest-bearing asset, and keeping its reserves to the minimum required level, the bank can maximize its income from interest but runs the risk of being unable to meet large, unanticipated withdrawals of deposits. Such a situation may be costly for the bank, as it gives rise to apprehension among depositors regarding the fragility of the bank's balance sheet, and depositors may thus be prompted to further withdraw their deposits. Therefore, the bank optimally allocates its resources between the interest-bearing asset and reserves, to maximize its expected interest income, while simultaneously taking into account the cost incurred in the case of reserve shortages.

Formally, the objective function of the bank is stated as follows:

$$
r_{L}\left(D_{i}-R_{i}\right)-r_{p, i} E\left[\operatorname{Max}\left(0, \tilde{X}_{i}-R_{i}\right)\right]
$$

where $r_{L}$ : interest rate on interest-bearing asset

$r_{P, i}$ : penalty rate for the $\mathrm{i}$-th bank in case of reserve shortage $\left(r_{p, i}>r_{L}\right)$

$R_{i}$ : reserve balance of the $\mathrm{i}$-th bank

$\tilde{X}_{i}$ : stochastic deposit withdrawal at the end of the period

The bank maximizes eq.(1) with respect to $R_{i}$ subject to the following required reserve constraint:

$$
R_{i} \geq \bar{\delta}_{i} D_{i}
$$

where $\bar{\delta}_{i}$ :required reserve ratio for the i-th bank

The first-order condition is given by ${ }^{5}$ 


$$
r_{p, i} \operatorname{Pr}\left[\tilde{X}_{i} \geq R_{i}\right]=r_{L}-\lambda
$$

where $\operatorname{Pr}[]$ indicates probability

$\lambda$ : non-negative Lagrangean multiplier associated with the required reserve constraint

The LHS of eq.(2) represents the decrease in the liquidity shortage cost brought about by increasing reserves, or the marginal benefit of increasing reserves, while the RHS provides the marginal cost of increasing reserves. When $\lambda>0$, the bank holds no more than the required amount of reserves. On the other hand, when the optimal reserve holdings $\left(R_{i}^{*}\right)$ exceed the required level, then $\lambda=0$. Figure 3 illustrates the way in which the optimal level of excess reserves is determined. When $\lambda=0$, it is easy to see from the figure that the demand for reserves depends upon the interest rate $\left(r_{L}\right)$ and the penalty rate $\left(r_{P, i}\right)$. The demand for reserves increases as the interest rate falls and the penalty rate rises. This model, while simple, can explain the surge in excess reserve holdings by Japanese banks that took place in the late '90s. The call rate was virtually zero under the zero-interest-rate policy, and the BOJ maintained the call rate to a level as low as possible under the new monetary policy regime. In the late 90s, banks with massive amounts of bad loans became insolvent, which may have led to a rise in the penalty rate. For this reason, depositors became very cautious about the balance sheet conditions of banks in an unstable financial system. If a bank’s reserves fell short of depositors’ withdrawals, then depositors may have perceived the balance sheet of the bank to be deteriorating. This perception would have accelerated the withdrawal of deposits, as well as the potential bankruptcy of the bank. To avoid such a disaster, banks would have set the penalty rate quite high and increased their demand for excess reserves.

\section{Estimation of Bank Demand Equations for Reserves}

\section{Derivation of Bank Demand Equations for Reserves}

To derive a bank's optimal demand equation for reserves, we must specify the way in which banks anticipate deposit withdrawals. We assume that the random variable $\tilde{X}_{i}$ has 
a Pareto distribution. Specifically, the density function of $\tilde{X}_{i}$ is written as

$$
f\left(\tilde{X}_{i}\right)=\frac{\theta X_{0, i}^{\theta}}{\tilde{X}_{i}^{\theta+1}} \quad X_{0, i}<\tilde{X}_{i}<\infty
$$

where $\theta, X_{0, i}$ : parameters of the distribution

$$
\theta>0, X_{0, i}>0
$$

By specifying the density function of deposit withdrawals, we may calculate the probability that deposit withdrawals exceed reserves, as follows:

$$
\operatorname{Pr}\left[\tilde{X}_{i} \geq R_{i}\right]=\left(\frac{R_{i}}{X_{0, i}}\right)^{-\theta}
$$

The substitution of eq.(4) into eq.(2) and the rearrangement of terms yields the following reserve equation:

$$
\log R_{i}=\log X_{0, i}-\frac{1}{\theta} \log \left(\frac{r_{L}-\lambda}{r_{p, i}}\right)
$$

It is quite likely that the bank's subjective distribution of $\tilde{X}_{i}$ depends on the bank's attributes. When the balance sheet of a bank deteriorates, the bank may anticipate a large amount of deposit withdrawals. In other words, the condition of a bank's balance sheet affects the distribution of its deposit withdrawals. We specify a bank's balance sheet condition using the bad loans ratio ( $B A D L O A N$ ). That is, we express $X_{0, i}$ as a function of deposits and the bad loans ratio.

$$
\begin{aligned}
& X_{0, i}=\alpha D_{I}^{\eta} B A D L O A N_{i}^{\varepsilon} \\
& \quad \text { where } \alpha>0, \eta>0, \varepsilon>0
\end{aligned}
$$

Deposits are included in eq.(6) as a scale factor. Substituting eq.(6) into eq.(5) and arranging terms, we obtain the following optimal demand equation for reserves: 


$$
\log R_{i}=\log \alpha+\eta \log D_{i}+\varepsilon \log \left(\text { BADLOAN }_{i}\right)-\frac{1}{\theta} \log \left(\frac{r_{L}-\lambda}{r_{p, i}}\right)
$$

For estimation purposes, we transform the demand equation for reserves into the deviation from required reserves. First, when $\lambda>0$, banks do not hold any excess reserves, so the deviation of optimal reserves from the required level is zero. In other words, the following equation is specified in logarithmic form:

$$
\log R_{i}-\log \bar{\delta}_{i} D_{i}=0
$$

Second, when the optimal demand for reserves exceeds the required level, the demand for excess reserves is expressed as

$$
\log R_{i}-\log \bar{\delta}_{i} D_{i}=\log \alpha-\log \bar{\delta}_{i}+(\eta-1) \log D_{i}+\varepsilon \log \left(B A D L O A N_{i}\right)-\frac{1}{\theta} \log \left(\frac{r_{L}}{r_{p, i}}\right)
$$

Since we can identify from the data which banks held excess reserves, we may estimate the system of reserve demand equations, (8) and (9), using a Tobit.

\section{Description of the Data}

We briefly explain the variables used in estimation. The variable $\left(R_{i}\right)$ represents the reserve balance of an individual bank at the BOJ. Deposits $\left(D_{i}\right)$ consist of all types of deposits, including certificates of deposit and debentures outstanding. The amount of required reserves is calculated based on the deposit balances and the requirement ratios provided in Table 1 , as was discussed in Section 2 . The required reserve ratio $\left(\bar{\delta}_{i}\right)$ is obtained by dividing the required reserves by deposits.

The bad loans ratio is calculated in two different ways: (1) the ratio of risk management loans to total loans $\left(B A D L O A N 1_{i}\right)^{6}$ and (2) the ratio of non-performing loans (NPL) under the Financial Reconstruction Law $\left(B A D L O A N 2_{i}\right){ }^{7}$ The variable 
$B A D L O A N 1_{i}$ is available for the period including and following 1997, while the variable $B A D L O A N 2_{i}$ is available for the period including and following 1998. Accordingly, the estimation period in each case begins with the year in which the bad loans ratio first becomes available. We also use the rate of change in the share price ( $\left.S H A R E_{i}\right)$ as a proxy for the market's perception of the banks' financial health. ${ }^{8}$ Table 3 presents the descriptive statistics for the bad loans ratio. The variable $B A D L O A N 1_{i}$ exhibited an increasing trend until 2001, in terms of both the mean and the median, while the same trend was observed for $B A D L O A N 2_{i}$ in terms of the median. Figure 4 presents the frequency distribution for bad loans ratios in 1998 and 2002, both of which are calculated from the risk management loans. There are considerable differences between the shapes of the frequency distributions in both years. In 2002, the peak of the frequency distribution rose, and the distribution was more skewed to the left. The correlation coefficient for these two measures is quite high (0.8982). However, the market's perception of banks' financial health does not necessarily closely reflect the bad loans ratio. In fact, the correlation coefficient between $B A D L O A N 1_{i}$ and $S H A R E_{i}$ is -0.1719 , and that between BADLOAN2 ${ }_{i}$ and $\mathrm{SHARE}_{i}$ is -0.1803 . $^{2}$

The penalty rate is likewise treated in two different ways. First, the penalty rate is treated as constant across banks and years. In this case, the penalty rate is subsumed into the constant term. Second, the ratio of operating profits to total equity is employed. The idea behind this is that the banks, the reserves of which are short of deposit withdrawals, will eventually go insolvent and lose their entire operating profits. The interest rate is the uncollateralized overnight call rate.

\section{$\underline{\text { Econometric Issues }}$}

We estimated eqs.(8) and (9) by pooled Tobit. The following procedure was used to classify banks, according to whether they have excess reserves. When a bank's actual reserves exceed the required reserves by at least $10 \%$, then it is identified as holding excess reserves. This conservative classification with respect to banks holding excess reserves reflects the unavailability of the daily deposit data upon which the reserve requirement should be based. ${ }^{9}$ During estimation, we added dummy variables to account 
for the different types of banks, i.e., dummy variables for city banks (DCITY), long-term credit banks (DCREDIT), and trusts (DTRUST). We also added the dummy variable (DPOLICY) to control for the monetary policy regime change that occurred in March 2001. Thereafter, the monetary base increased substantially in order to satisfy the target set for the current accounts balance at the BOJ.

\section{Estimation Results}

Table 4 presents the estimation results for banks' demands for reserves. The estimation is conducted for six specifications, where three variables are used to represent the banks' financial health, and where two account for the penalty rate. The estimation results are quite satisfactory, in the sense that the coefficient estimates of the three key variables determining the demand for reserves are statistically significant, irrespective of the model specification. Deposits exert a significantly positive effect on reserve holdings. The call rate has a negative effect on the demand for reserves, as is predicted from the theoretical model in Section $3 .^{10}$ The two bad loans ratios also affect the demand for reserves positively, which implies that banks with higher bad loans ratios increased their reserves. Furthermore, increases in the rate of change in share prices decreased the demand for reserves, though this effect is insignificant.

Table 5 tabulates the elasticities of reserve demands with respect to deposits, the call rate, and the bad loans ratio, for the four types of banks holding excess reserves. These elasticities are calculated on the basis of the results of the estimation with BADLOAN1 $1_{i}$ as the bad loans ratio, and the ratio of operating profits to total equity as the penalty rate. ${ }^{11}$ 12 The deposit elasticity is generally close to one, except for city banks, in which case it is much less than one (0.4491). The interest-rate elasticity ranges from -0.1816 to -0.4146 , while the elasticity with respect to the bad loans ratio ranges from 0.2149 to 0.5010 . The magnitude of this elasticity is smaller for city banks because, of these, a lower proportion of banks held excess reserves. 
5. The Effects of the Short-term Interest Rate and Bank Financial Health on the Demand for Excess Reserves: A Quantitative Evaluation

In the previous section, we found that both the short-term interest rate and banks' financial health are significant explanatory variables of the demand for reserves. Based on the parameter estimates of the demand equation for reserves, and using simulation analysis, we evaluated quantitatively the extent to which changes in the short-term interest rate and/or banks' bad loans ratios affected the demand for excess reserves.

Specifically, we took the following steps. First, we calculated the theoretical values of excess reserves by substituting the actual exogenous variables for 2002 into the estimated demand equation for reserves, or eq.(9), and subtracted the required reserves. Next, we calculated the predicted value of excess reserves under different scenarios of the call rate and the bad loans ratio. We assumed that the call rate was raised to its level prior to the adoption of the zero-interest-rate policy. In other words, the call rate was set to its level in March 1998, or to $0.05 \% .{ }^{13}$ With regard to the banks' financial health, we considered a case in which the bad loans ratio was halved. This scenario is consistent with the Koizumi Structural Reform Plan, introduced in October 2002, which specified that non-performing loans should be reduced by $50 \%$ within one year.

The predicted excess reserves thus calculated were summed up across banks, and the aggregated excess reserves were compared with their baseline value. Table 6 indicates the extent to which banks' excess reserves are reduced under the different scenarios for the call rate and the bad loans ratio, and under four different specifications of the reserve demand equation. When the call rate is raised, excess reserves are reduced by as much as $40 \%$ in the constant penalty case, and by about $30 \%$ in the variable penalty case. Although the magnitude of the reduction in excess reserves is slightly less for the case in which the banks' financial health is improved, it is not negligible in this case. Excess reserves are reduced by $13 \%$ to $29 \%$. When increases in both the call rate and banks' financial health are implemented simultaneously, the holdings of excess reserves are reduced almost by half. 


\section{Concluding Remarks}

We empirically investigated why Japanese banks held excess reserves in the late '90s. We were able to pin down two factors that explain the demand for excess reserves: a low short-term interest rate, or call rate, and banks' fragile financial health. The nearly zero call rate substantially increased the demand for reserves, and the high bad loans ratio also contributed to the observed increase in reserve holdings. A quantitative evaluation of these factors was also conducted. It was found that excess reserve holdings may be halved by raising the call rate to its level prior to the zero-interest-rate policy, and by decreasing the bad loans ratio by $50 \%$. The Japanese financial system is gaining stability as banks rapidly eliminate bad loans, and this elimination should lead to a reduction in excess reserve holdings. 


\section{Footnotes}

${ }^{1}$ There are two spikes in the figures, each of which corresponds to Year 2000 and Fiscal Year 2002 problems. On those occasions, the policy authority provided ample liquidity to meet a surge in demand and secure stability in the financial markets.

${ }^{2}$ See Shirakawa (2002) for a detailed discussion of the factors that have contributed to an increase in banks' reserve demands since the late ' 90 s.

${ }^{3}$ Hosono et al. (2001), Hayashi (2001), and Uesugi (2002) investigated the liquidity effect using daily reserve data. The relationship between the equilibrium short-term interest rate and the reserve supply may be obtained by aggregating banks' reserve demands. Our focus in this study was to examine what motivates individual banks to hold excess reserves.

${ }^{4}$ The following model of reserve demands comes from Chapter 8 in Freixas and Rochet (1997).

${ }^{5}$ It can be shown that the objective function of the bank is a concave function of reserves, so the solution to the first-order condition is guaranteed to be a maximum of the objective function.

${ }^{6}$ Risk management loans include loans to borrowers in legal bankruptcy, past-due loans in arrears by six months or more, loans in arrears by three months or more but less than six months, and restructured loans.

${ }^{7}$ The NPLs under the Financial Reconstruction Law are defined as the sum of the assets classified as "bankrupt/de facto bankrupt," "doubtful," and "special attention."

${ }^{8}$ Some banks are not listed on the stock exchange, so these are excluded from the sample in the estimation of the demand equation for reserves incorporating the share price.

${ }^{9}$ To check for robustness, we also used a more conservative definition of excess reserves. In this case, banks with actual reserves exceeding the required reserve by $50 \%$ were identified as banks holding excess reserves. Under this definition, the estimation results remained qualitatively unchanged.

${ }^{10}$ Loan and Wood (2002) also reported that the interest rate has a significantly negative effect on the reserve demands of commercial banks in the U.S.A.

${ }^{11}$ The elasticities are calculated by multiplying the adjustment factor by the original parameter estimates. See Chapter 16 of Wooldridge (2002) for a discussion of adjustment factors.

${ }^{12}$ The elasticities based on the other specifications are calculated in a similar way. They are not reported here, since they follow the same pattern as that reported in the text. These elasticity estimates are available upon request from the author.

${ }^{13}$ It is assumed that the penalty rate does not change. 


\section{References}

[1] Freixas, X. and J.-C. Rochet(1997). Microeconomics of Banking, The MIT Press.

[2] Hayashi,F.(2001).” Identifying a Liquidity Effect in the Japanese Interbank Market,” International Economic Review 42, pp.287-315.

[3] Hosono,K., Sugihara,S. and T.Mihira(2001) Kinyu Seisaku no Yukosei to Genkai (Effectiveness and Limits of Monetary Policy), Toyo Keizai Shinposha, (in Japanese).

[4] Lown,C.S. and J.H.Wood(2003).” The Determination of Commercial Bank Reserve Requirements,” Review of Financial Economics 12, pp.83-98.

[5] Shirakawa,M.(2002).” Ryoteki Kanwa Saiyogo 1 nenkan no Keiken (Experience during One Year after Adoption of Quantitative Easing Policy),” in Komiya,R. and Nippon Keizai Center(eds.) Kinyu Seisaku Rongi no Soten: Nichigin Hihan to sono Hanron (Issues of Monetary Policy Debates: Criticism of the Bank of Japan and Rebuttal) , Nippon Keizai Shinbunsha, pp.157-234. (in Japanese)

[6] Uesugi,I.(2002).” Measuring the Liquidity Effect: The Case of Japan,” Journal of the Japanese and International Economies 16, pp.289-316.

[7] Wooldridge,J.M.(2002). Econometric Analysis of Cross Section and Panel Data, The MIT Press. 
Figure 1 Excess Reserve Ratio

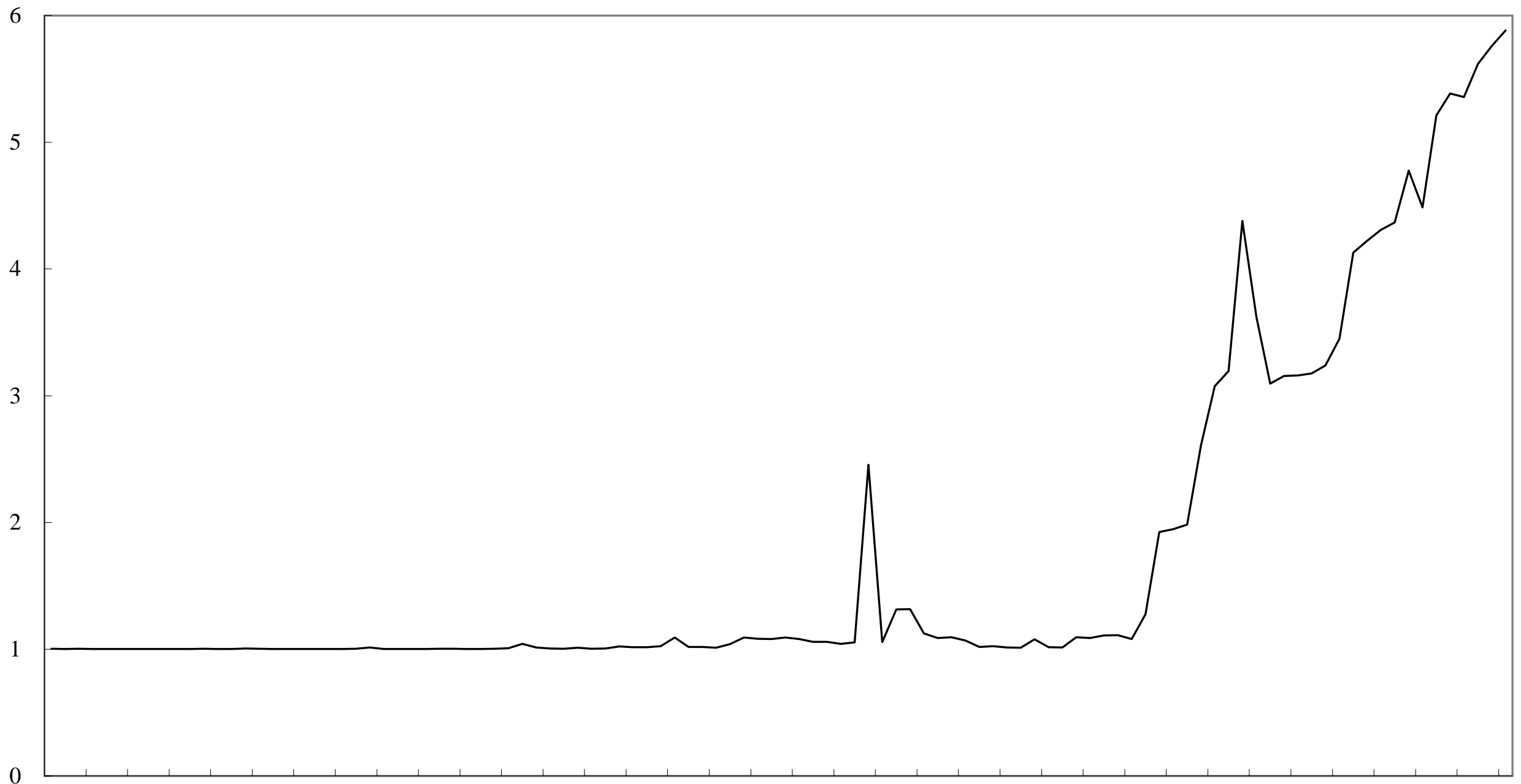

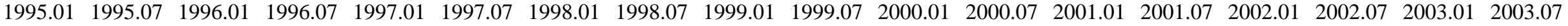

The Excess reserve ratio is defined as the ratio of actual reserve to required reserve.

Data Source: The Bank of Japan Homepage 
Figure 2 Frequency Distribution of Excess Reserve Ratio in 1994

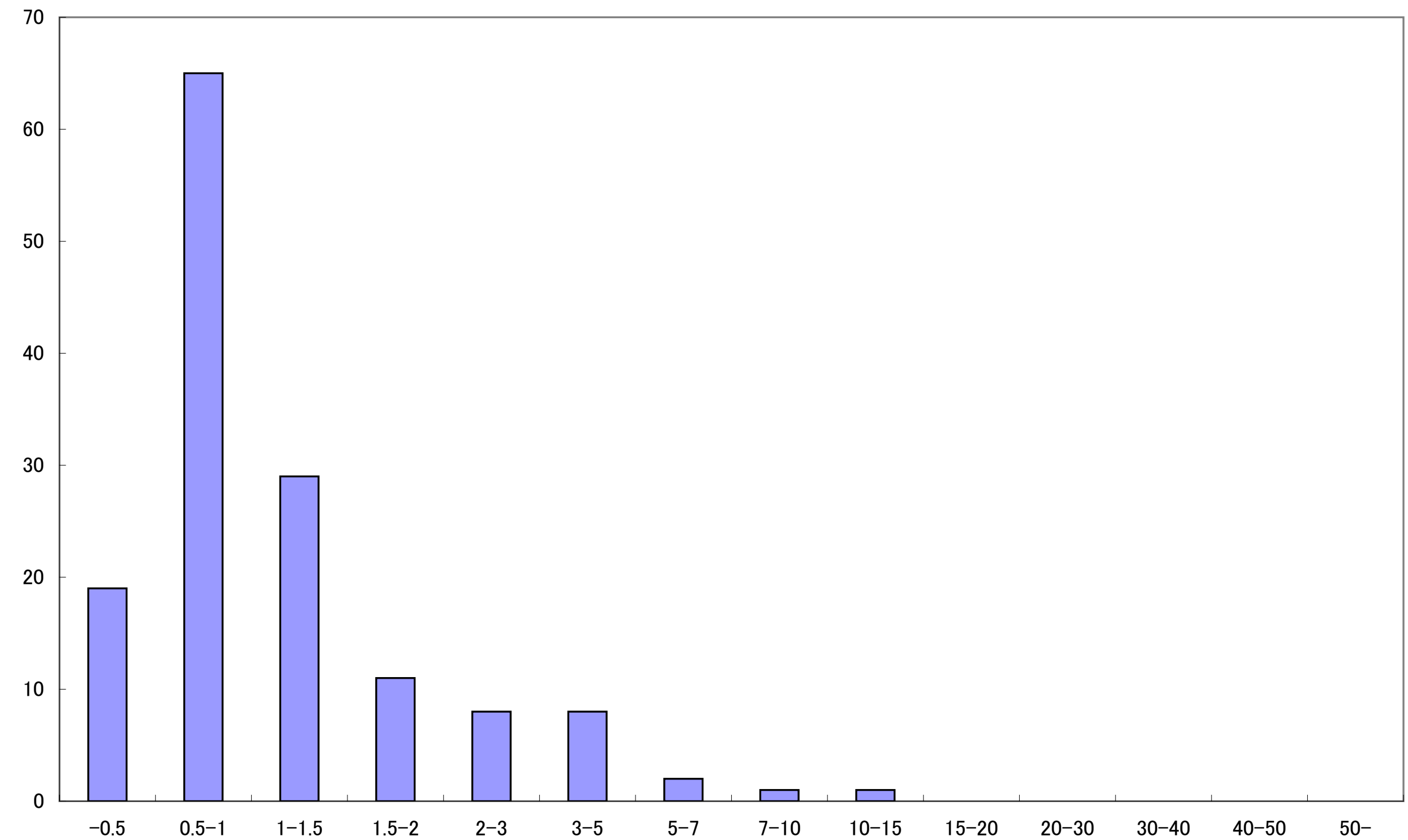


Figure 2 Frequency Distribution of Excess Reserve Ratio in 1999

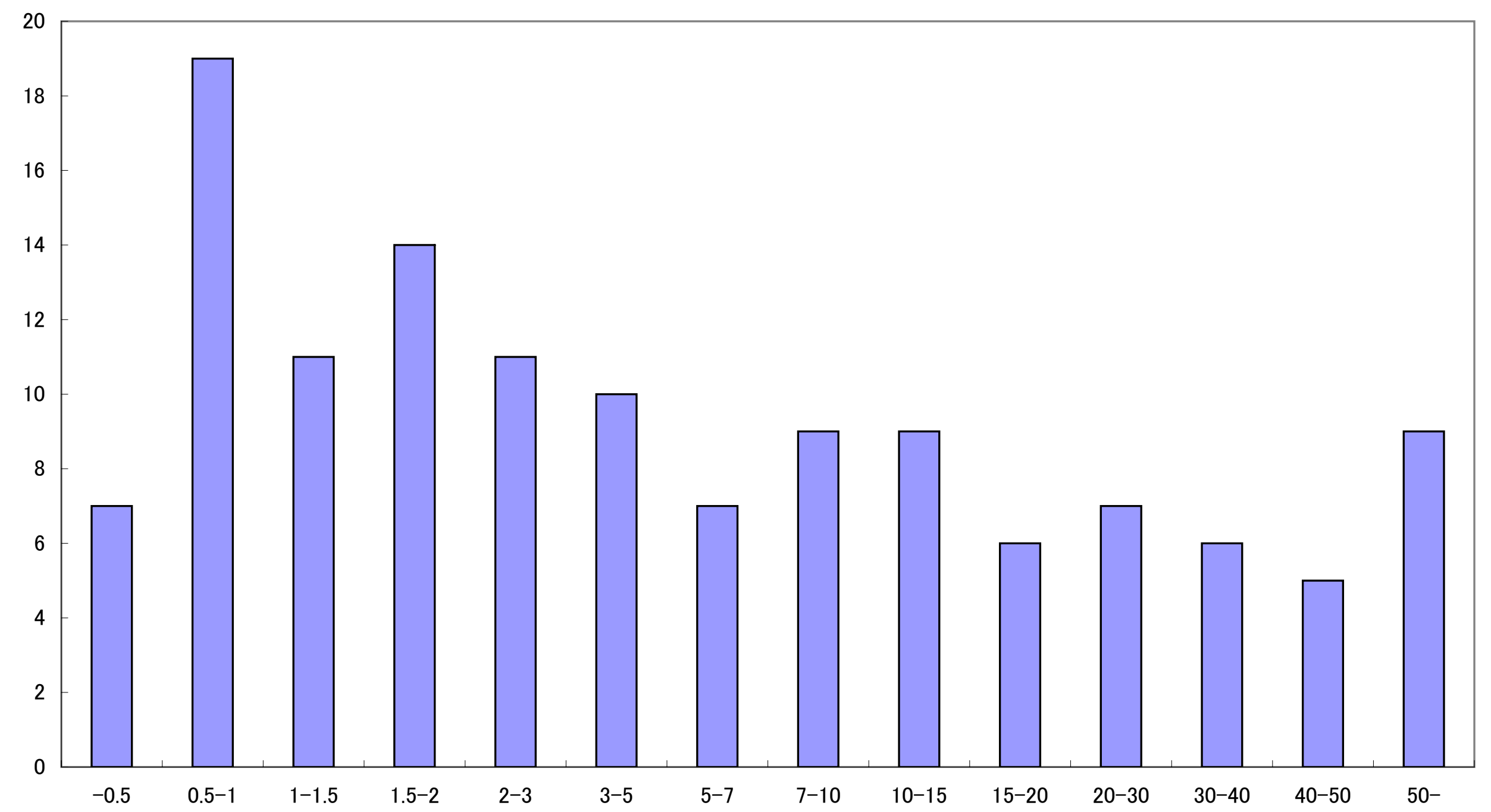


Figure 2 Frequency Distribution of Excess Reserve Ratio in 2001

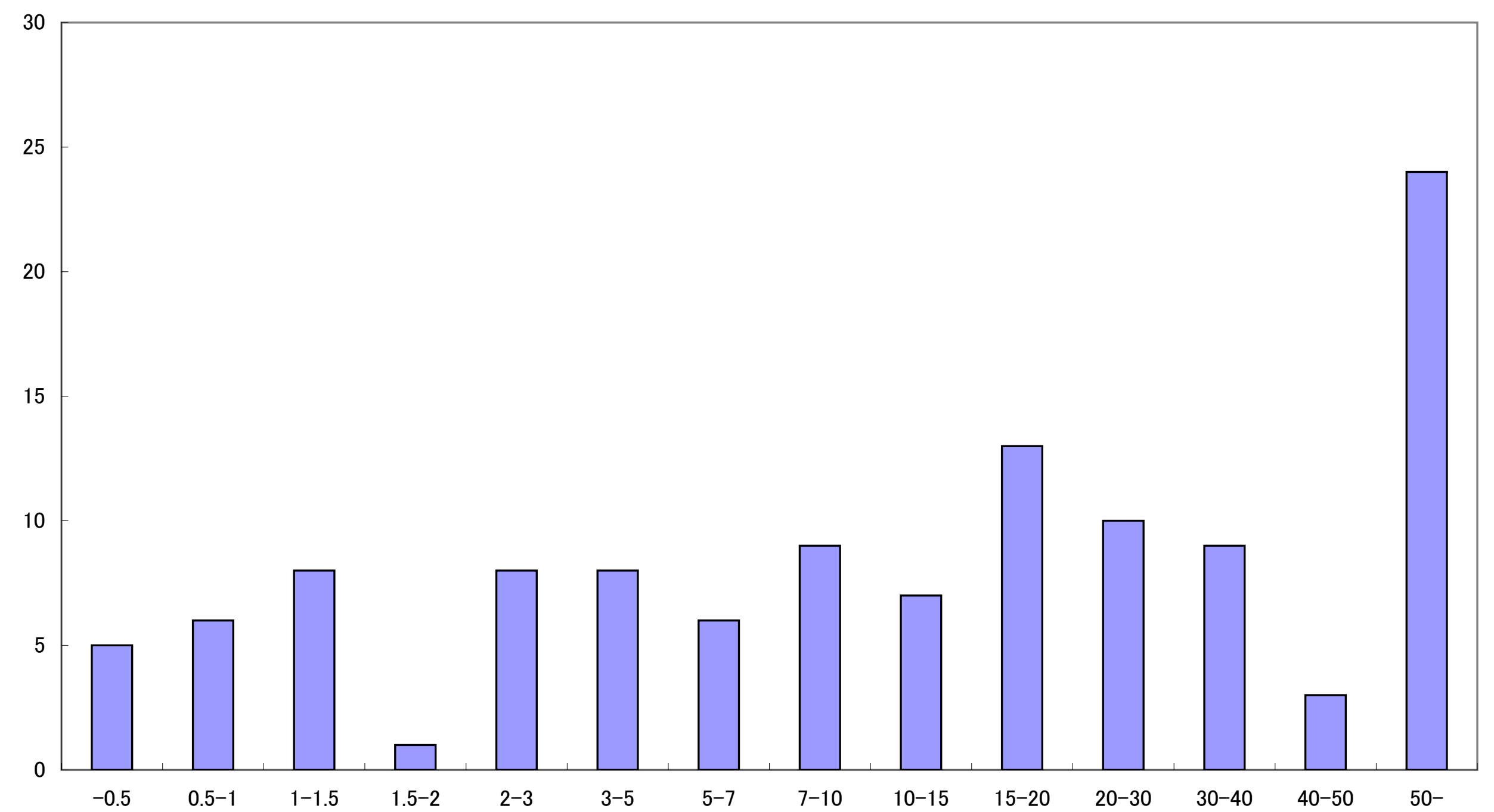


Figure 3

Determination of Optimal Demand for Reserve

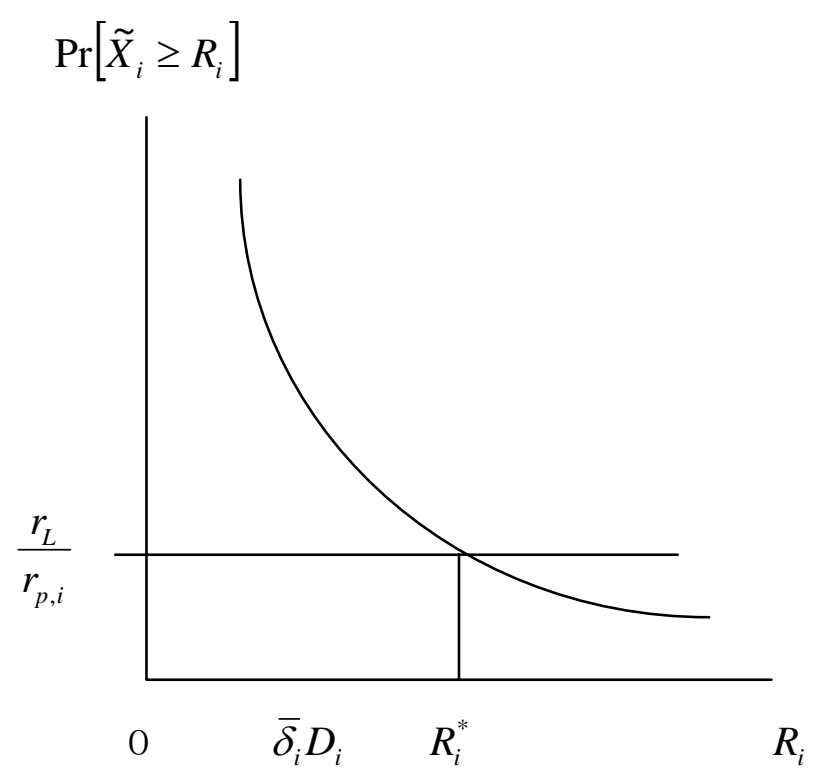


Figure 4

Frequency Distribution of Bad Loans Ratio in 1998

Based upon Risk Management Loans

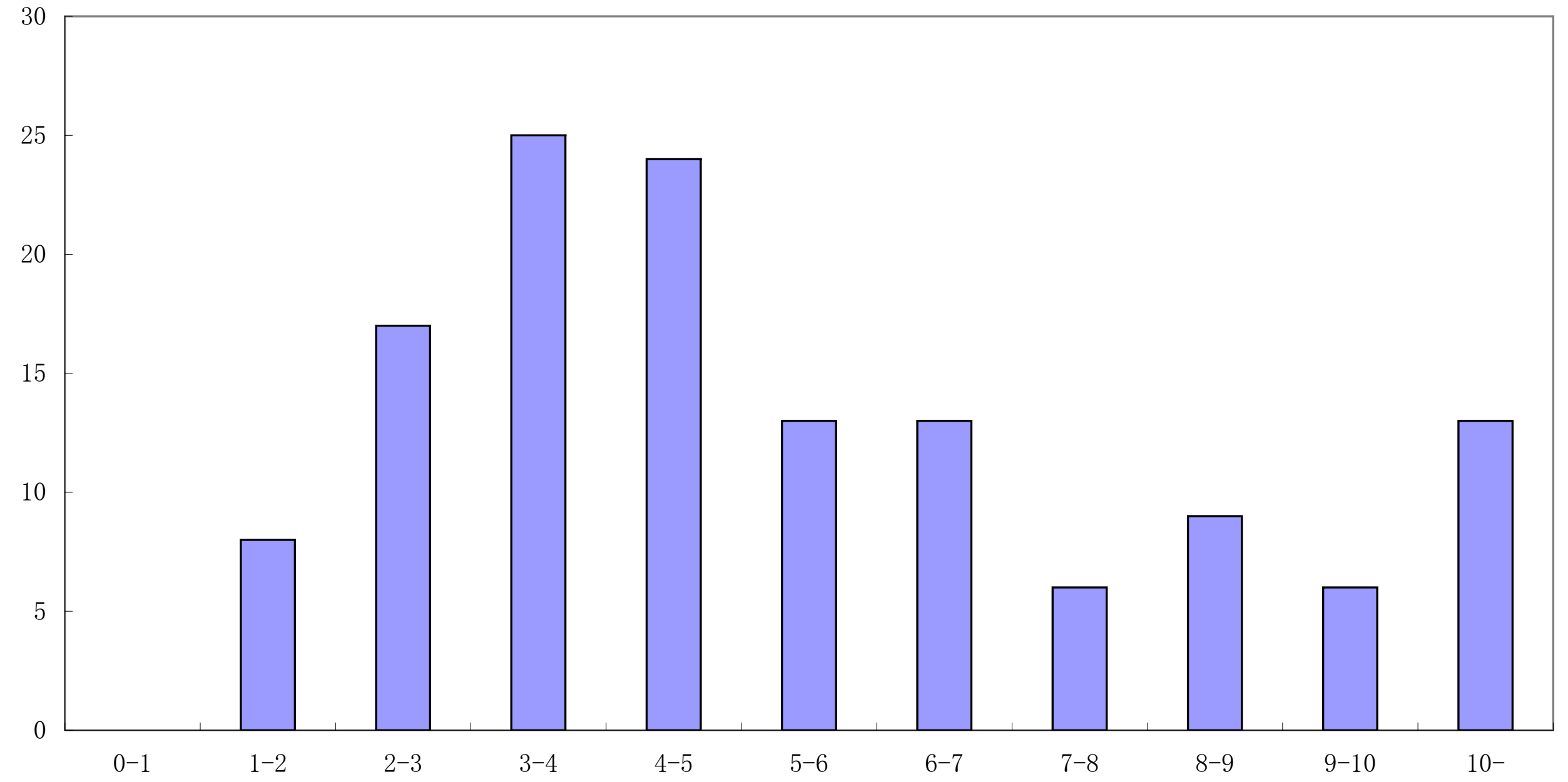

Data Source: Nikkei Financial Data 
Figure 4

Frequency Distribution of Bad Loans Ratio in 2002

Based upon Risk Management Loans

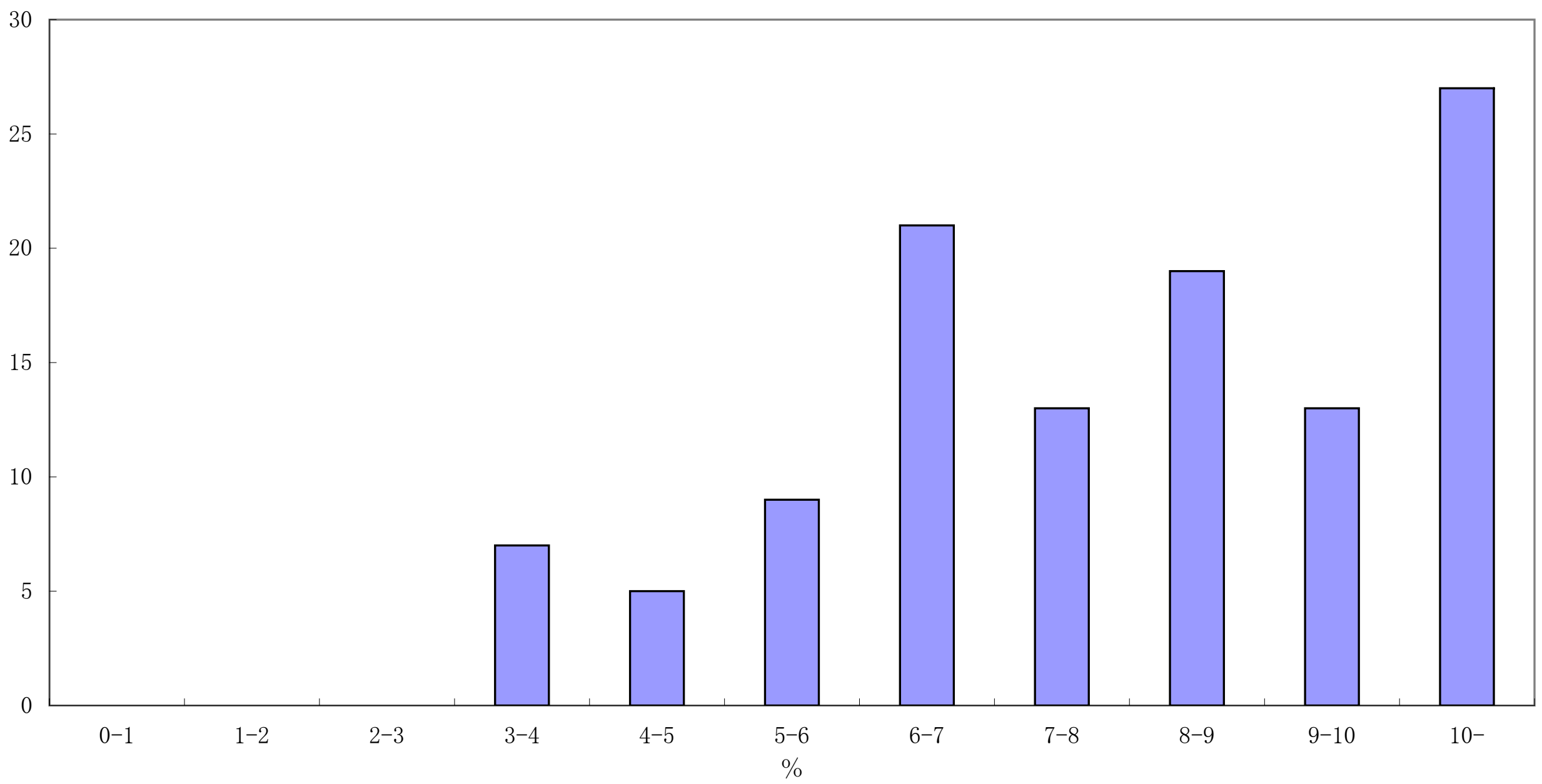


Table 1

Reserve Requirement Ratios

(1) Reserve Ratios on Deposits

\begin{tabular}{|l|l|c|}
\hline Type of deposits & Amount of deposits & Reserve ratio (\%) \\
\hline $\begin{array}{l}\text { Time Deposits } \\
\text { including Certificates } \\
\text { of Deposit }\end{array}$ & 2.5 trillion yen - & 1.2 \\
\cline { 2 - 3 } & $\begin{array}{l}1.2-2.5 \\
\text { trillion yen }\end{array}$ & 0.9 \\
\cline { 2 - 3 } & $\begin{array}{l}500 \text { billion } \\
-1.2 \text { trillion yen }\end{array}$ & 0.05 \\
\cline { 2 - 3 } & $\begin{array}{l}50-500 \text { billion yen } \\
\text { Other deposits }\end{array}$ & 0.05 \\
\hline & 2.5 trillion yen - & 1.3 \\
\cline { 2 - 3 } & $\begin{array}{l}1.2-2.5 \\
\text { trillion yen }\end{array}$ & 1.3 \\
\hline & $\begin{array}{l}500 \text { billion } \\
-1.2 \text { trillion yen }\end{array}$ & 0.8 \\
\hline & \begin{tabular}{l}
50 - 500 billion yen \\
\hline
\end{tabular} & 0.1 \\
\hline
\end{tabular}

(2) Reserve Ratios on Debentures Outstanding

\begin{tabular}{|l|c|}
\hline \multicolumn{1}{|c|}{ Type of banks } & Reserve ratio (\%) \\
\hline $\begin{array}{l}\text { Banks, } \\
\text { long-term credit banks } \\
\text { and foreign exchange bank }\end{array}$ & 0.1 \\
\hline
\end{tabular}

Notes: The reserve ratios in the table are effective on October 16, 1991.

Data Source: The Bank of Japan Homepage 
Table 2

Descriptive Statistics of Banks’ Excess Reserve

\begin{tabular}{|c|cc|}
\hline Fiscal year & $\begin{array}{r}\text { Ratio of actual reserve to required reserve } \\
\text { Median }\end{array}$ & \begin{tabular}{c} 
Standard deviation \\
\hline 1991
\end{tabular} \\
1992 & 0.9564 & 2.82 \\
1993 & 0.9730 & 2.79 \\
1994 & 0.9337 & 2.76 \\
1995 & 0.9085 & 1.56 \\
1996 & 0.9828 & 5.36 \\
1997 & 0.9960 & 7.23 \\
1998 & 1.0191 & 8.65 \\
1999 & 1.1884 & 25.78 \\
2000 & 3.9963 & 39.38 \\
2001 & 1.1936 & 24.59 \\
2002 & 15.1764 & 39.25 \\
\hline
\end{tabular}

Data Source: Nikkei Financial Data 
Table 3

Descriptive Statistics of Bad Loans Ratio

(\%)

\begin{tabular}{|c|c|c|c|c|}
\hline \multirow[t]{2}{*}{$\begin{array}{c}\text { Fiscal } \\
\text { year }\end{array}$} & \multicolumn{2}{|c|}{$\begin{array}{l}\text { ratio of risk management } \\
\text { loans to total loans } \\
\left(B A D L O A N 1_{i}\right)\end{array}$} & \multicolumn{2}{|c|}{$\begin{array}{l}\text { ratio of non-performing loans } \\
\text { under Financial Reconstruction } \\
\text { Law to total loans } \\
\left(B A D L O A N 2_{i}\right)\end{array}$} \\
\hline & Mean & Median & Mean & Median \\
\hline 1998 & 6.1 & 4.5 & 7.5 & 5.6 \\
\hline 1999 & 7.7 & 6.0 & 10.0 & 6.6 \\
\hline 2000 & 8.1 & 6.9 & 9.4 & 7.6 \\
\hline 2001 & 8.7 & 8.1 & 10.0 & 9.0 \\
\hline 2002 & 8.2 & 8.1 & 9.0 & 8.8 \\
\hline
\end{tabular}

Notes: Risk management loans include loans to borrowers in legal bankruptcy, past due loans in arrears by 6 months or more, loans in arrears by 3 months or more and less than 6 months, and restructured loans.

The non-performing loans under the Financial Reconstruction Law are defined as the sum of the assets classified as "bankrupt/de facto bankrupt", "doubtful”, and "special attention."

Data Source: Nikkei Financial Data 
Table 4 Estimation Results of Optimal Demand Equation for Reserve

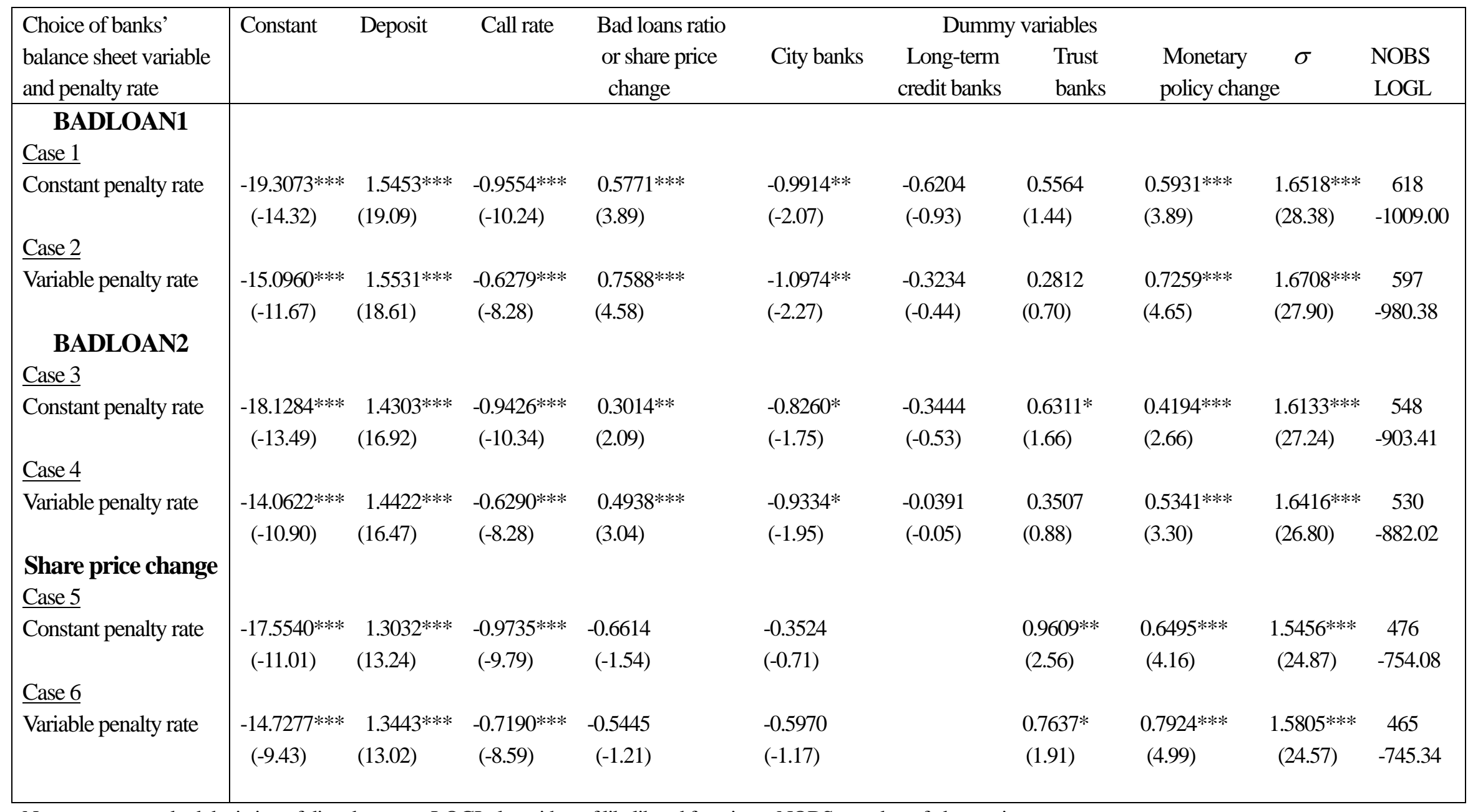

Notes: $\quad \sigma$ : standard deviation of disturbance $\quad$ LOGL: logarithm of likelihood function $\quad$ NOBS: number of observations

Values in parentheses are t-values. *,**, ***: significant at 10\%, 5\%, and $1 \%$ level, respectively 
Table 5

Estimates of Reserve Demand Elasticity

\begin{tabular}{|l|ccc|}
\hline Types of banks & Deposit & $\begin{array}{c}\text { Call } \\
\text { rate }\end{array}$ & $\begin{array}{l}\text { Bad loan } \\
\text { ratio }\end{array}$ \\
\hline City banks & 0.4491 & -0.1816 & 0.2194 \\
Long-term credit & 1.0255 & -0.4146 & 0.5010 \\
Banks & 0.8902 & -0.3599 & 0.4349 \\
Trust banks & 0.9462 & -0.3825 & 0.4623 \\
Regional banks & & & \\
\hline
\end{tabular}

Notes: The elasticity is calculated for banks holding excess reserve on the basis of estimation results with $B A D L O A N 1_{i}$ as the bad loan ratio and the ratio of operating profits to total equity as penalty rate. 
Table 6

Effects of Call Rate Increase and Reduction of Bad Loans Ratio on Demand for Excess Reserve: Quantitative Evaluation by Simulation Analysis

$(\%)$

\begin{tabular}{|l|ccc|}
\hline $\begin{array}{l}\text { Choice of banks' } \\
\text { balance sheet variable } \\
\text { and penalty rate }\end{array}$ & $\begin{array}{c}\mid c \\
\text { increase of call rate } \\
\text { to } 0.05 \%\end{array}$ & $\begin{array}{c}\text { reduction of } \\
\text { bad loans ratio } \\
\text { by } 50 \%\end{array}$ & total \\
\hline \multicolumn{1}{|c|}{ BADLOAN1 } & & -22.8 & -51.7 \\
$\frac{\text { Case 1 }}{\text { Constant penalty rate }}$ & -40.1 & -28.8 & -47.9 \\
$\frac{\text { Case 2 }}{\text { Variable penalty rate }}$ & -29.6 & & -45.9 \\
\multicolumn{1}{c|}{ BADLOAN2 } & -39.4 & -12.8 & \\
$\frac{\text { Case 3 }}{\text { Constant penalty rate }}$ & & & -41.9 \\
$\frac{\text { Case 4 }}{\text { Variable penalty rate }}$ & -29.3 & -19.9 & \\
\hline
\end{tabular}

